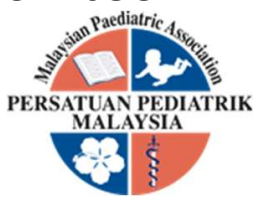

\title{
LUC ABSCESS: A RARE COMPLICATION OF A COMMON PEDIATRIC EAR INFECTION
}

\author{
Nurfadhilah Aisyah Murad', Zalilah Musa', Khairudin Abdullah', Irfan Mohamad²
}

\begin{abstract}
Middle ear infection occurs when fluid accumulate in middle ear as a result of inflammatory response to viral or bacterial infection. Infections may spread from the middle ear, resulting in a subperiosteal collection beneath the temporal muscle. Luc abscess is a rare complication of otitis media. The difference of this complication with other extracranial abscesses relating to otitis media is, it may not be associated with mastoid bone involvement. Therefore, it is defined as benign complication of otitis media. Here, we report a case of 10-month-old baby boy diagnosed with Luc abscess with mastoid involvement.
\end{abstract}

Keywords: Otitis media; infant; abscess; mastoiditis DOI: $10.51407 /$ mjpch.v27i1.127

\section{Introduction}

Otitis media is one of the most frequently diagnosed and treated childhood diseases [1]. Although it is often self-limiting, there are important complications of the disease due to its proximity to the intracranial and intratemporal compartments. Complications of otitis media can be divided into intracranial and extracranial [1]. The extracranial complications are further divided into intratemporal or extratemporal complications. Subperiosteal abscesses are extracranial extratemporal complications, and Luc abscess is one of its rare form.

\section{Case Report}

A 10-month-old baby boy presented with history of left temporal swelling for two days, associated with fever and rhinorrhoea for four days. There was no ear pain or discharge. The child was still active and tolerated feeding. Other siblings were having upper respiratory infection, as noticed by the mother. Otherwise, the patient has no history of ear infection or trauma.
Received: 30 October 2020; Accepted revised

manuscript: 1 April 2021

Published online: 28 April 2021
Examination showed fullness at left temporal area, tender, firm-to-hard in consistency, measuring about $5 \mathrm{~cm} \times 5 \mathrm{~cm}$ but not erythematous, not inflamed and no skin changes. Left pinna was displaced outward, forward and downward (Figure 1). Otoscopy revealed a sagging posterosuperior wall of left external auditory canal (EAC) with bulging and inflamed bilateral tympanic membranes (TM) (Figure 2). Laboratory analysis revealed leucocytosis.

Initial diagnosis of left temporal abscess with bilateral acute otitis media was made. Visual reinforcement audiometry (VRA) test revealed normal hearing bilaterally. Computed tomography (CT) brain and temporal showed presence of ill-defined, heterogenous, hypodense

\footnotetext{
'Department of Otorhinolaryngology, Hospital Kemaman, Jalan Da' Omar, 24000 Kemaman, Terengganu, Malaysia.

${ }^{2}$ Department of Otorhinolaryngology-Head \& Neck Surgery, School of Medical Sciences, Universiti Sains Malaysia Health Campus, 16150 Kota Bharu, Kelantan, Malaysia.

Corresponding Author:

Prof. Dr. Irfan Mohamad, Department of

Otorhinolaryngology-Head \& Neck Surgery, School of Medical Sciences, Universiti Sains Malaysia Health Campus, 16150 Kubang Kerian, Kelantan, Malaysia.

Tel: +609-767 6420 Email: irfankb@usm.my
} 
collection at the left temporal region measuring about $2.1 \mathrm{~cm}(\mathrm{~W}) \times 3.0 \mathrm{~cm}(\mathrm{AP}) \times 2.8 \mathrm{~cm}$ (L) (Figure 3). This collection extended into left mastoid air cells causing bone erosion and occupied left middle ear cavity. This collection has eroded the adjacent mastoid part and squamous part of left temporal bone.

The diagnosis was revised to bilateral acute otitis media complicated with left Luc abscess and bilateral mastoiditis due to presence of collection at left temporal region which causing bone erosion of adjacent mastoid part and squamous part of left temporal bone. Hence, under general anaesthesia, the patient underwent incision and drainage of left temporal abscess with bilateral myringotomy for the bulging TM. The incision for abscess drainage was made at left temporal region. One loculated abscess was identified and drained $5 \mathrm{ml}$ of pus.

Following the surgery, intravenous ceftazidime was completed within fourteen days. The patient was discharged with oral cefuroxime for another two weeks and daily normal saline dressings at nearest clinic. The post-operative first week follow-up demonstrated that his wound already closed, no pus discharge, not erythematous or inflamed. Child remained active and afebrile. Otoscopy revealed no ear discharge, with both TM were intact and not inflamed. On subsequent follow up, a repeat VRA was done, and his hearing remained normal. Culture of the abscess showed no growth. Tuberculosis test for culture was also negative.

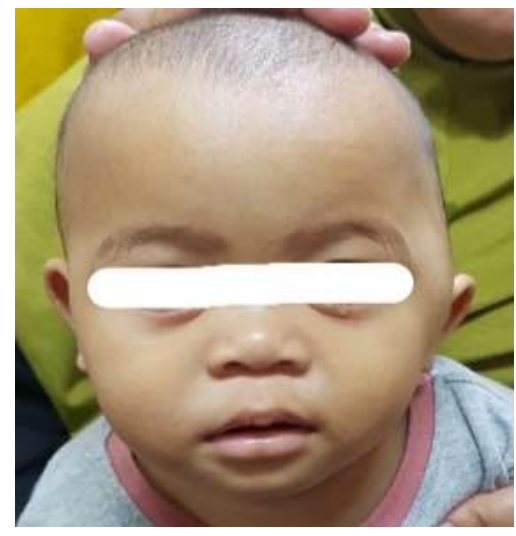

Figure 1. Child with left temporal swelling (red arrow) with displaced pinna.
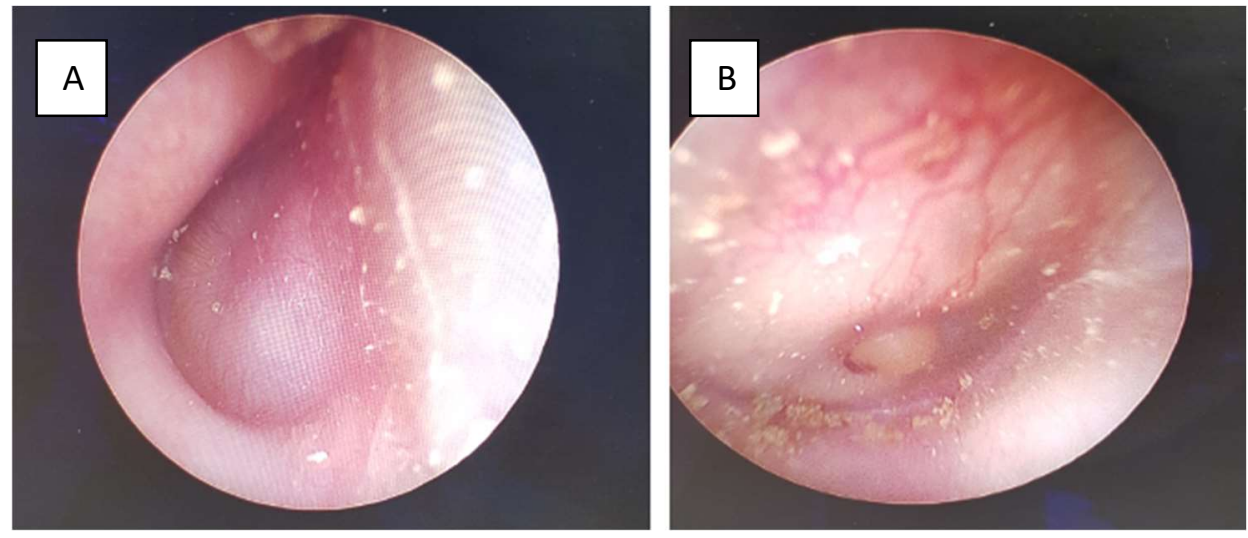

Figure 2. Left otoscopy showed bulging TM and sagging of posterosuperior EAC wall (A). Right otoscopy also noted the bulging and inflamed TM (B). 


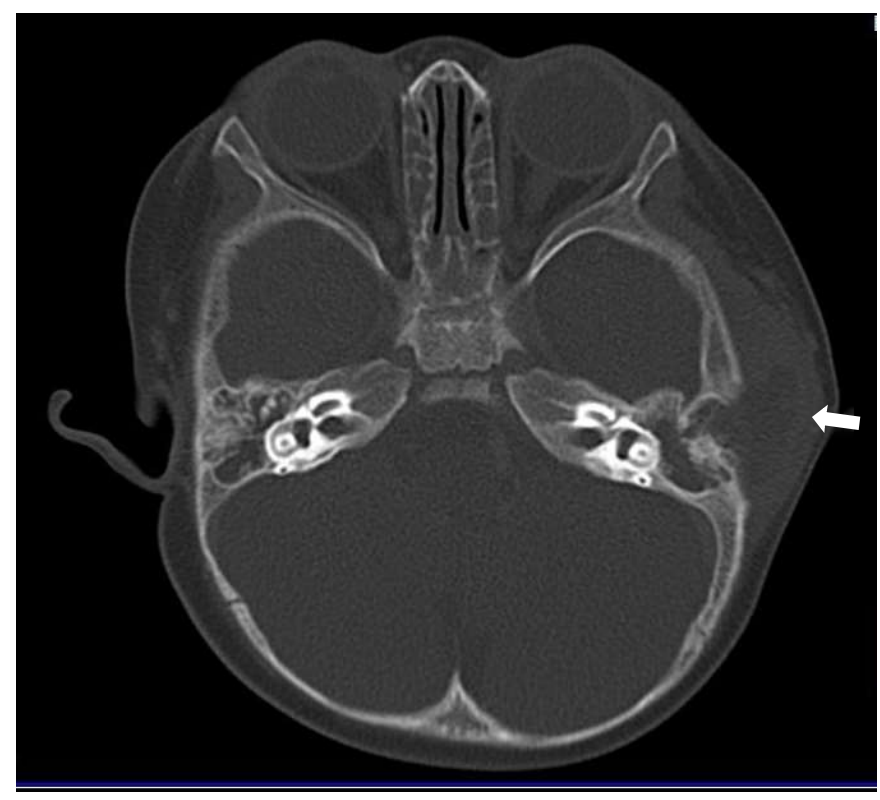

Figure 3. An ill-defined, heterogenous, hypodense collection (white arrow) at the left temporal region. The collection extends into left mastoid air cells causing bony erosion. The collection appeared to erode adjacent mastoid part and minimal squamous part of left temporal bone.

\begin{abstract}
Discussion
Luc abscess was first described by Henri Luc in 1913 as subperiosteal complication of acute otitis media [2]. According to Luc, the disease differs from other extracranial abscess in that it develops without the mastoid bone involvement [2]. He believed the infection spreads via submucosal tissues after having found no evidence to suggest a correlation between the subperiosteal temporal abscess and the development of mastoiditis. The notch of Rivinus and branches of the deep auricular arteries were the presumed pathways connecting EAC with the subperiosteum deep to the temporal muscles allowing for the infectious spread. Through publication, Luc hoped that in the pre-antibiotic era he could spare patients from the unnecessary and dangerous bone operations of the time [2].
\end{abstract}

In our case, patient had brief history of fever and rhinorrhoea, then developed left temporal swelling for two days. Otoscopy revealed bilateral acute otitis media which suggested the source of acute mastoiditis leading to subperiosteal abscess.

In relation to mastoiditis, there are six different types of abscess that can be considered. Each of the six types differ from the anatomical landmarks, and some have certain clinical features. First is posterior auricular abscess, the commonest among the six. This abscess caused displacement of pinna forward, outward and downward. In children, posterior auricular abscess occurred in MacEwen triangle. Second is zygomatic abscess, which occurred in front of and above pinna. It is associated with oedema of upper eyelid. Third is Bezold abscess. It usually occurred deep to sternocleidomastoid and pushing sternocleidomastoid forward which causing patient to have torticollis. The infection follows the posterior belly of digastric and the abscess collected between tip of mastoid process and angle of mandible. It can be present in upper part of posterior neck triangle and usually associated with purulent otorrhea. Fourth is Citelli abscess, which occurs behind mastoid, more toward occipital region. Fifth is retropharyngeal or parapharyngeal abscess which is a deep neck abscess of a parapharyngeal spaces. This abscess usually results from infection of peritubal cells due to acute mastoiditis. Sixth is Luc abscess or also called meatal abscess, where a swelling can be seen between antrum and external osseous meatus.

The diagnosis of Luc abscess in our patient was made based on history, clinical presentation and evidence from CT temporal bone. Many clinicians 
have little experience in the diagnosis and treatment of this disease due to its rarity owing to widespread use of antibiotic nowadays. Mengi et al summarizes the cases of Luc abscess (Table 1) [1]. It can be concluded that a subperiosteal temporal abscess is not necessarily without mastoid involvement as previously thought. Instead, there is possibility of alternative pathways for infectious spread through direct extension from the mastoid to the subperiosteal temporal

region.

Table 1. Reported cases of Luc abscess

\begin{tabular}{|c|c|c|c|c|c|}
\hline & Age/Sex & Etiology & Treatment & Mastoiditis & Culture \\
\hline $\begin{array}{l}\text { Mengi et al. }{ }^{1} \\
2018\end{array}$ & 11-year-old & AOM & $\begin{array}{l}\text { Abscess } \\
\text { drainage, } \\
\text { tympanostomy, } \\
\text { tube insertion, } \\
\text { cortical } \\
\text { mastoidectomy, } \\
\text { IV antibiotic. }\end{array}$ & Yes & No growth \\
\hline $\begin{array}{l}\text { Knappe et al. } \\
1997\end{array}$ & $\begin{array}{l}\text { 15-year-old } \\
\text { female }\end{array}$ & - & $\begin{array}{l}\text { Mastoidectomy, } \\
\text { IV antibiotic }\end{array}$ & No & - \\
\hline $\begin{array}{l}\text { Asha'ari et al. }{ }^{3} \\
2012\end{array}$ & $\begin{array}{l}\text { 73-year-old } \\
\text { male }\end{array}$ & AOM & $\begin{array}{l}\text { Abscess } \\
\text { drainage, } \\
\text { cortical } \\
\text { mastoidectomy, } \\
\text { IV antibiotic }\end{array}$ & Yes & $\begin{array}{l}\text { Klebsiella } \\
\text { azaenae }\end{array}$ \\
\hline $\begin{array}{l}\text { Weiss et } \text { al. }^{4} \\
2010\end{array}$ & 5-year-old boy & AOM & $\begin{array}{l}\text { Abscess } \\
\text { drainage, } \\
\text { tympanostomy, } \\
\text { tube insertion, IV } \\
\text { antibiotic }\end{array}$ & No & $\begin{array}{l}\text { Fusobacterium } \\
\text { necrophorum }\end{array}$ \\
\hline $\begin{array}{l}\text { Santhi et al. } 5 \\
2012\end{array}$ & 5-year-old boy & $\begin{array}{l}\text { Congenital } \\
\text { cholesteatoma }\end{array}$ & $\begin{array}{l}\text { Modified radical } \\
\text { mastoidectomy }\end{array}$ & Yes & - \\
\hline $\begin{array}{l}\text { Scrafton et al. }{ }^{7} \\
2014\end{array}$ & 4-year-old boy & $\mathrm{AOM}$ & $\begin{array}{l}\text { Abscess } \\
\text { drainage, } \\
\text { tympanostomy, } \\
\text { tube insertion, } \\
\text { cortical } \\
\text { mastoidectomy, } \\
\text { IV antibiotic. }\end{array}$ & Yes & $\begin{array}{l}\text { Streptococcus } \\
\text { pyogenes }\end{array}$ \\
\hline Er et al..$^{8} 2016$ & 9-year-old boy & AOM & $\begin{array}{l}\text { Abscess } \\
\text { drainage, } \\
\text { tympanostomy, } \\
\text { tube insertion, IV } \\
\text { antibiotic }\end{array}$ & No & No growth \\
\hline This report & $\begin{array}{l}\text { 10-month-old } \\
\text { boy }\end{array}$ & AOM & $\begin{array}{l}\text { Abscess } \\
\text { drainage, } \\
\text { myringotomy, IV } \\
\text { antibiotic }\end{array}$ & Yes & No growth \\
\hline
\end{tabular}


Luc abscess is often associated with reduced or compromised immune status such as paediatric age group, elderly, and in patients with other comorbid like diabetes mellitus [1]. Asha'ari et al reported one elderly case with underlying diabetes mellitus presented with acute otitis media complicated with subperiosteal abscess [3]. While eight cases out of ten listed above (Table 1) were from paediatric age group [1]. Both aerobic and anaerobic bacteria have been found as the causative agents in the abscess cultures. Therefore, broad spectrum antibiotics should be used for the empirical treatment until the final aspirate culture and microbiological advice reports return [1].

Eight out of ten cases in Table 1, had acute otitis media as the etiology. Five cases developed mastoiditis with four cases undergone mastoidectomy. We concluded that otitis media as common cause which can lead to serious complication, thus leading to needing surgical intervention. There was also one case of 15-yearold patient reported by Knappe et al underwent mastoidectomy and no mastoid bone involvement was observed [2]. Knappe and Gregor supported Luc theory of infectious spread, suggesting subperiosteal temporal abscess of otitic origin with the absence of mastoid involvement [2].

In our patient, he had bilateral mastoiditis with left temporal subperiosteal abscess and underwent abscess drainage and bilateral myringotomy. Intravenous antibiotic was commenced for two weeks and later he was discharged well with oral antibiotic for another two weeks. Therefore, the decision to perform mastoidectomy may differ from patient to patient based on clinical history, examination, CT findings and must always outweigh risk and benefit of performing mastoidectomy.

\section{Conclusion}

Although acute otitis media is common, its complication especially Luc abscess is extremely rare. The clinically rare encounter may cause this complication to be missed or untreated. Thus, the highlight of this case is to share our experience in dealing with Luc abscess. Temporal CT is a useful imaging tool in determining the complication of the disease and its treatment strategy.

\section{References}

[1] Mengi E, Tümkaya F, Sağtaş E, Ardıç FN. An unusual complication of otitis media: Luc's abscess. J Int Adv Otol 2018;14(3):497-500. https://doi.org/10.5152/iao.2018.4785

[2] Knappe M, Gregor R. Luc's abscess - a rare complication of middle ear infection. J Laryngol Otol 1997;111(5):461-4. https://doi:10.1017/S0022215100137648

[3] Asha'ari ZA, Shiyuti MI, Zihni M. Luc's abscess: a reminder of potential complication of otitis media. Brunei Int Med J. 2012;8:261-4.

[4] Weiss I, Marom T, Goldfarb A, Roth Y. Luc's abscess: the return of an old fellow. Otol Neurotol. 2010;31:776-9. doi: 10.1097/MAO.0b013e3181e40a5d.

[5] Santhi K, Tang IP, Nordin A, Prepageran N. Congenital cholesteatoma presenting with Luc's abscess.J Surg Case Rep. 2012;2012:rjs026.

[6] Garner EF, McKinnon BJ. Luc's abscess-a case report.Int J Pediatr Otorhinolaryngol Extra. 2013;8:e5-7. doi: 10.1016/j.pedex.2012.11.001.

[7] Scrafton DK, Qureishi A, Nogueira C, Mortimore S. Luc's abscess as an unlucky complication of mastoiditis. Ann R Coll Surg Engl. 2014:96(5):e28-e30. https://doi.org/10.1308/003588414X1394618 $\underline{4901281}$

[8] Er A, Erdağ TK, Çağlar A, Kümüş O, Duman M. Luc abscess: an extraordinary complication of acute otitis media. Am J Emerg Med. 2016;34:117.e1-3. doi: 10.1016/j.ajem.2015.05.029. 